\title{
The influence of soccer field ground types on lower extremity muscle activation during forward side step
}

\author{
Hyun-Been Lee, \& Bee-Oh Lim* \\ Chung-Ang University
}

\begin{abstract}
[Purpose] The purpose of this study was to investigate the lower extremity muscles activity during forward side step by soccer field ground types. [Methods] Fifteen elite high school soccer players participated in this study. Muscle activation patterns were recorded at $2000 \mathrm{~Hz}$ during forward side step task. Surface EMG of the tibialis anterior(TA), soleus(SOL), medial gastrocnemius(MG), lateral gastrocnemius(LG), peroneus brevis(PB) muscle was recorded, and the root mean square of the EMG was normalized, using a maximum voluntary isometric contraction(\%MVIC). One-way repeated ANOVA was used for comparison among three soccer field ground types(natural grass, artificial turf, hard ground). [Results] Artificial turf displayed greater soleus and peroneus brevis activities compare to natural grass during forward side step task. [Conclusions] The relationship between increased soleus and peroneus brevis activation and greater incidence of injury in artificial turf versus natural grass requires further study. Soccer players routinely training on artificial turf for prolonged periods should be carefully monitored.
\end{abstract}

Key words: Soccer, Ground types, Lower extremity, Muscle activity

\section{서 론}

축구장은 지면의 형태에 따라 잔디구장과 맨땅구장 으로 나눌 수 있고, 잔디구장은 인조잔디와 천연잔디로 나눌 수 있다. 각각의 그라운드는 형태에 따라 충격 흡 수성 (Shock Absorption), 미끄럼 저항(Slip Resistance), 견인력(Traction) 뿐만 아니라 반발계수(Restitution $\mathrm{Co}^{-}$ efficient) 등이 다르기 때문에, 그라운드형태는 선수들의 경기력과 부상에 많은 영향을 미친다(Kang, 2008). 현재 가장 많이 사용되는 인조잔디 (35 55mm 장파일)는 초 기의 인조잔디 $(19 \mathrm{~mm}$ 단파일 나일론 재질 - 수세미같은 마찰력으로 슬라이딩 시에 화상을 입기도 함)에 비해 안 정성 및 충격 흡수력이 향상 되어 넘어지더라도 안전하지

논문 투고일 : 2019. 02. 04.

논문 수정일 : 2019. 03. 19.

게재 확정일 : 2019. 04. 15.

* 교신저자 : 임비오(bolim@cau.ac.kr).

* 이 논문은 이현빈의 2018년도 석사학위논문에서 발췌하여 수 정 보완하였음.
만(Kang, 2008), 천연잔디보다는 부상이 더 많이 발생한 다(Korea Sports Safety Foundation, 2016).

현재까지 진행된 그라운드의 형태에 따른 연구들을 구 분해보면, 그라운드 형태에 따른 경기력 비교 연구(Park, 2007; Lee et al., 2006; Jang et al., 2011; Andersson et al., 2008; McNitt et al., 2004; Reyneri \& Bruno, 2004), 그라운드의 형태에 따른 부상관련 비교연구(Park et al., 2011; Choi, 2010; Aoki et al., 2010; Dragoo \& Braun, 2010; Ekstrand et al., 2011; Fuller et al., 2007a, 2007b; Soligard et al., 2010; Steffen et al., 2007), 신발과 지면사이의 운동역학적 변인 비교연구(Jin et al., 2006; Dowling et al., 2010; Ford et al., 2006; Fuller et al., 2010; Villwock et al., 2009) 등이 있다. 이상의 연구들은 실험을 기반으로 한 운동역학적, 생 리학적 연구와 축구경기 데이터를 기반으로 한 코호트 연 구로 나누어진다. 실험을 기반으로 한 운동역학적 연구결 과, Dowling et al.(2010)은 전방십자인대 손상의 위험 은 신발과 지면의 마찰력이 높을수록 위험성 또한 크다 
고 보고하였으며, Villwock et al. (2009)는 천연잔디에 비해서 인조잔디에서 운동할 때 신발과 지면사이의 회전 강성, 최대토크, 회전견인력 등이 더 크다고 보고하였다. 또한 Park et al.(2011)은 인조잔디가 천연잔디보다 근 피로를 유발시키는 혈중 젖산과 암모니아의 수치를 더 증 가시킨다고 보고하였다.

현재까지 선행연구에서 그라운드의 형태에 따라 지면의 반발계수, 회전강성, 최대 토크 등이 다르다고 보고하였다 (Apell et al., 1992; Newham et al., 1983; Villwock et al., 2009). 이러한 요인들은 하지의 근 활성도와 상관이 있으며, 근 활성도가 클수록 부상의 위험이 커지기 때문에 (Apell et al., 1992; Newham et al., 1983) 그라운드의 형태는 하지의 부상 발생에 직접적인 영향을 주는 요인이 라고 할 수 있다. 특히, 본 연구에서 측정한 하지의 경우 충격력을 흡수하는 하퇴의 말단에 있는 근육들로 지면의 부하를 가장 먼저 받기 때문에(Lee et., 2013) 인조잔디 에서 훈련하는 운동선수들이나 생활체육 동호인들은 천 연잔디에서 할 때에 비해 부상을 예방하기 위한 근력 트 레이닝과 스트레칭이 중요하며, 그중에서도 가자미근과 단비골근의 선택적 강화는 꼭 필요하다고 판단되어 본 연 구를 수행하였다. 또한, 기존의 선행연구에서는 지면반 력, 영상분석, 비디오분석, 혈액분석의 관점에서 인조잔 디와 천연잔디를 비교하였는데, 아직까지 그라운드의 형 태별 (인조잔디, 천연잔디, 맨땅구장) 근 활성도의 차이를 분석한 연구는 전무한 실정이다. 또한 우리나라의 특성상 생활체육인들은 맨땅구장에서도 축구경기를 많이 하고 있기 때문에(Korea Sports Safety Foundation, 2016) 천연잔디와 인조잔디 그리고 맨땅구장 세 가지 그라운드 형태를 분석하는 것은 의미가 있다.

따라서 본 연구의 목적은 축구경기 중 공격과 수비동작 에서 자주 사용하는 동작인 전진 사이드 스텝 시 그라운드 형태(천연잔디, 인조잔디, 맨땅구장)에 따른 하지근육의 근 활성도 차이를 분석하는 것이다.

\section{연구방법}

\section{연구대상}

연구 대상자는 고등학교에 재학 중인 신체 건강한 축 구 선수 15 명 (나이: $17.7 \pm 0.8$ 세, 신장: $171.5 \pm 6.3 \mathrm{~cm}$, 체
중: $66.9 \pm 4.3 \mathrm{~kg}$ )을 선정하였다. 연구대상자들은 최근 6 개월간 하지의 기능장애가 없고, 대퇴와 하퇴의 정형 외 과적 진단에 의해 근육·골격계에 특별한 이상이 없다고 판단된 대상들을 임의표본추출법으로 모집하였다. 이 연 구의 모든 절차는 실험을 수행하기 전에 연구자가 소속 된 기관에서 연구윤리위원회의 연구의 목적 및 연구 설 계에 대한 연구승인을 받은 후 시행하였다(IRB 승인번호: 1041078-201801-HR-018-01).

\section{실험 도구}

근육의 활성도를 측정하기 위하여 근전도 시스템(DTS Probe Transmitter, Noraxon, USA)을 사용하였다. 축 구화(AF 5122, Adidas, China)는 선수들이 가장 많이 사 용하는 것을 선정하였으며 (Seon, 2018), 스터드는 원형 으로 연구대상자들의 축구화 사이즈 별로 준비하여 일정 하게 통제하였다〈Fig. 1 top〉. 축구훈련 시 가장 많이 사 용하는 스텝 레더를 사용하여 그라운드의 형태별로 전진 사이드스텝을 통해 하지 근 활성도를 측정하였다〈Fig. 1 bottom〉.
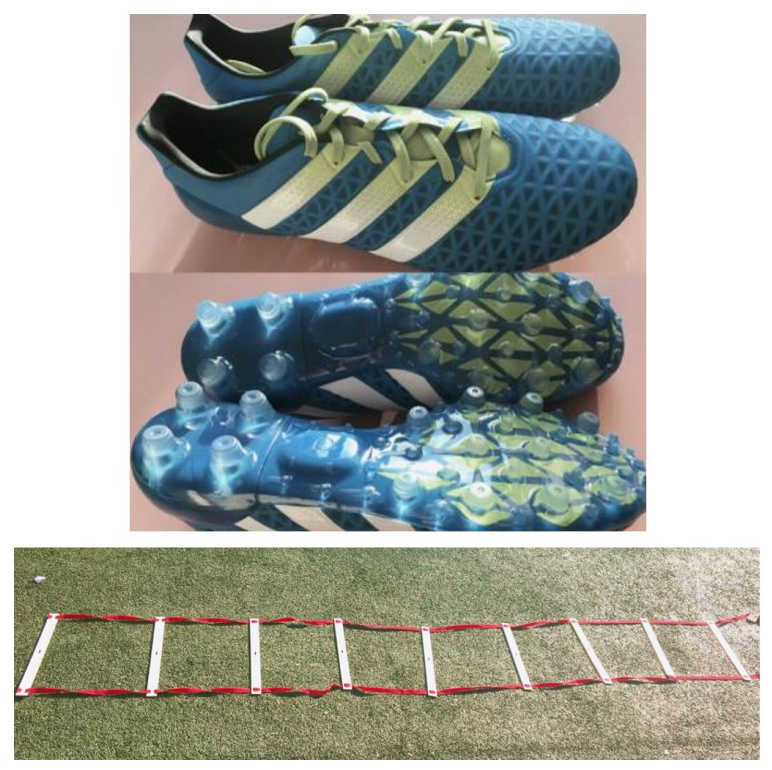

Fig. 1. Soccer shoe (top) and step ladder (bottom)

\section{실험 절차}

연구대상자들의 신체 특성 파악 후 실험절차에 대해 사전 교육을 실시하였고. 연구 대상자들에게 실험에 대한 
목적, 정확한 자세, 동작 구간에서의 속도에 대한 설명과 함께 전진 사이드 스텝(Forward side step) 시범을 보여 주었으며, 전진 사이드 스텝이 익숙해 질 수 있도록 연습 시켰다.

본 실험 전에 연구대상자들의 5 가지 근육(전경골근, 가 지미근, 내비복근, 외비복근, 단비골근)에 전극을 연결한 후 근육별로 최대등척성수축 $(\mathrm{MVC})$ 을 실시하여 하지의 각 근육별로 5 초간 최대 근력 시 나타나는 근전도 파형을 저장하였다. 최대등척성수축을 측정 후 24시간이 지난 후 3 가지 축구장 (맨땅, 인조잔디, 천연잔디)에서 전진 사 이드 스텝(Forword side step test)를 3회 수행하였다. 연구대상자들의 실험 순서는 무작위로 선정하였다. 전극 의 부착 위치는 Seniam의 자료를 참고하였다(Hermens et al., 1999). 표면 전극 사이의 거리는 $2 \mathrm{~cm}$ 를 유지하였 으며, 전극은 근육의 기점 (origin)과 착점 (insertion)의 중간부위에 부착하였다〈Fig. 2〉.

\section{자료 처리}

양질의 근전도 자료를 획득하기 위하여 전극 부착 전 알코올을 사용하여 피부표면을 닦은 후 피부 외피를 깨끗 하게 정리하였다. 근전도 신호는 초당 $1,500 \mathrm{~Hz}$ 로 수집하 였으며, 원근전도(raw data)는 $20 \sim 350 \mathrm{~Hz}$ 대역통과 필 터링 (bandpass filter)후 정류(full wave rectification)하 였다. 평활화(smothing)는 RMS(root mean square)을 이용하였다. 시간 범위(time window)는 $50 \sim 100 \mathrm{~ms}$ 으 로 설정하였다. 그 후 실험 전 측정한 최대 수의적 수축 값 $(\mathrm{MVC})$ 과 비교하여 분석하였다. 분석 구간은 3 번째 스텝
의 오른쪽 발가락이 스텝레더의 오른쪽에 닿는 순간부터 10 번째 스텝의 오른쪽 발가락이 스텝레더의 오른쪽에서 떨어지는 순간까지이다.

\section{통계 처리}

SPSS(Version 23.0) 프로그램을 이용하여 통계처리 하였다. 축구장의 형태(맨땅, 인조잔디, 천연잔디)에 따 른 하지 근력의 활성도는 오른쪽 발가락이 스텝레더의 오 른쪽에 닿는 순간부터 10 번째 스텝의 오른쪽 발가락이 스 텝레더의 오른쪽에서 떨어지는 순간까지의 구간별 평균 값을 산출하였으며, 3 가지 축구장의 형태별 통계적 차이 를 알아보기 위해서 반복이 있는 일원변량분석(One-way repeated measures ANOVA)을 실시하였고, 사후검증 은 Scheffe 방식을 활용하였다. 본 연구의 유의수준은 $\alpha$ $=.05$ 로 설정하였다.

\section{연구결과}

축구장 형태에 따른 하지 근활성도를 비교한 결과는 〈Table 1)과 같다. 가자미근과 단비골근에서 평균 근 활 성도 값은 통계적으로 유의한 차이가 있는 것으로 나타났 다 $(p<.05)$. 사후분석결과 가지미근과 단비골근에서 인 조잔디가 천연잔디보다 하지의 평균 근 활성도가 더 크게 나타났다. 전경골근, 외비복근, 내비복근에서는 3 가지 그 라운드 형태별 평균 근 활성도 값은 통계적으로 유의한 차 이가 없는 것으로 나타났지만 인조잔디에서의 평균 근 활 성도가 천연잔디와 맨땅보다 더 큰 수치를 보였다.

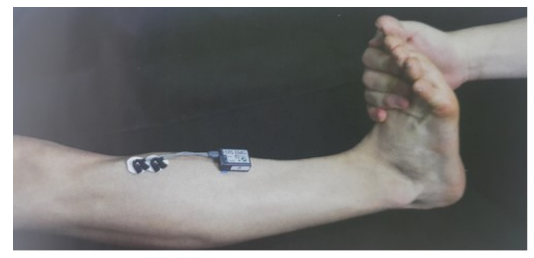

전경골근

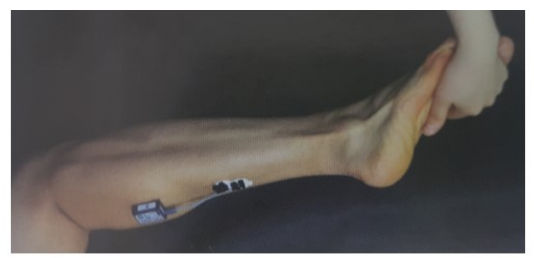

가자미근

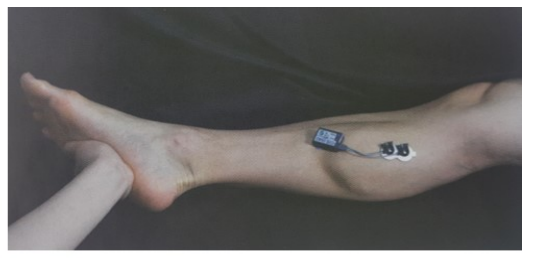

내비복근

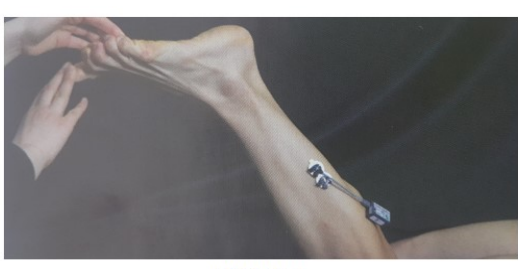

외비복근

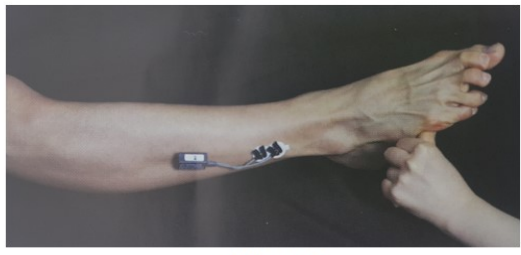

단비골근

Fig. 2. Electrode attachment site (Kim et al., 2013) 
Table 1. The mean difference of lower extremity muscle activities among soccer ground field types (Unit: \%MVC)

\begin{tabular}{|c|c|c|c|c|c|}
\hline \multirow[b]{2}{*}{ Variables } & \multicolumn{3}{|c|}{ Soccer field types } & \multirow[b]{2}{*}{$F$} & \multirow[b]{2}{*}{$p$} \\
\hline & $\begin{array}{c}\text { Natural } \\
\text { grass (a) }\end{array}$ & $\begin{array}{c}\text { Artificial } \\
\text { turf (b) }\end{array}$ & $\begin{array}{c}\text { Hard } \\
\text { ground (c) }\end{array}$ & & \\
\hline TA & $\begin{array}{l}31.25 \\
\pm 7.35\end{array}$ & $\begin{array}{l}35.73 \\
\pm 7.45\end{array}$ & $\begin{array}{l}34.04 \\
\pm 8.49\end{array}$ & 1.269 & $\begin{array}{l}\text { a-b: } .23 \\
\text { b-c: } .84 \\
\text { c-a: } .62\end{array}$ \\
\hline SL & $\begin{array}{c}65.79 \\
\pm 24.64\end{array}$ & $\begin{array}{c}88.19 \\
\pm 19.18\end{array}$ & $\begin{array}{c}84.10 \\
\pm 17.88\end{array}$ & 4.712 & $\begin{array}{l}\text { a-b: } .02 \\
\text { b-c: } .88 \\
\text { c-a: } .08\end{array}$ \\
\hline MG & $\begin{array}{c}73.00 \\
\pm 31.54\end{array}$ & $\begin{array}{c}85.27 \\
\pm 32.51\end{array}$ & $\begin{array}{c}81.71 \\
\pm 36.28\end{array}$ & .536 & $\begin{array}{l}\text { a-b: } .60 \\
\text { b-c: } .96 \\
\text { c-a: } .81\end{array}$ \\
\hline LA & $\begin{array}{c}43.64 \\
\pm 11.19\end{array}$ & $\begin{array}{c}54.57 \\
\pm 15.10\end{array}$ & $\begin{array}{c}50.08 \\
\pm 13.31\end{array}$ & 2.500 & $\begin{array}{l}\text { a-b: } .10 \\
\text { b-c: } .68 \\
\text { c-a: } .45\end{array}$ \\
\hline PB & $\begin{array}{c}55.27 \\
\pm 18.81\end{array}$ & $\begin{array}{c}74.57 \\
\pm 22.01\end{array}$ & $\begin{array}{c}58.92 \\
\pm 16.73\end{array}$ & 4.076 & $\begin{array}{l}\text { a-b: } .03 \\
\text { b-c: } .10 \\
\text { c-a: } .87\end{array}$ \\
\hline
\end{tabular}

TA: tibialis anterior, SL: soleus, MG: medial gastrocnemius, LA: lateral gastrocnemius, PB: peroneus brevis,

${ }^{*} p<.05$

\section{논 의}

본 연구는 총 15 명의 10 대 남자 고등학교학생들을 대상으로 그라운드의 형태(천연잔디, 인조잔디, 맨땅)에 따라 스텝 레더에서 전진 사이드 스텝동작을 실시한 후 그 에 따른 하지근육인 전경골근(TA), 가자미근(SL), 내비 복근 $(\mathrm{MG})$, 외비복근 $(\mathrm{LA})$, 단비골근 $(\mathrm{PB})$ 의 평균 근 활성 도를 분석하였다. 본 연구결과, 가자미근과 단비골근의 근 활성도에서 인조잔디는 천연잔디에 비해 통계적으로 유의하게 더 높게 나타났다.

전경골근의 경우 하지의 평균 활성도는 그라운드의 형 태 3가지 (천연잔디, 인조잔디, 맨땅)별로 서로 비교분석한 결과 통계적으로 유의한 차이는 나타나지 않았다. $\mathrm{Ma} \&$ $\mathrm{An}$ (2012)의 연구에서 높은 굽의 신발을 신을수록 발목이 저측굴곡(plantarflexion)된 상태로 중력중심이 앞쪽으로 이동하기 때문에 비복근이 수축된 상태로 있게 되며, 전경 골근은 이 반대로 신장된 상태로 있게 되어, 발목의 저측 굴곡 각도가 클수록 전경골근의 긴장도가 정상수준으로 낮아졌다고 보고하였다. 즉, 발목이 저측굴곡된 상태에서 는 전경골근이 많이 사용되지 않는 것이다. 본 연구에서
실시한 전진 사이드 스텝동작은 높은 굽의 신발을 신은 것 과 유사한 형태로 발의 뒤꿈치를 들면서 앞꿈치로 몸을 지지하고 있는 저측굴곡 형태로 운동을 수행하게 된다. 그 결과 전진 사이드 스텝은 전경골근의 사용 비율이 낮게 나 타났으며, 평균 근 활성도에서도 그라운드의 형태 3가지 (천연잔디, 인조잔디, 맨땅)별로 서로 비교분석한 결과 통 계적으로 유의한 차이가 없었다.

가자미근은 발목의 저측굴곡 시 주동근의 역할을 하며, 1 개의 관절을 지나는 한관절 근육(One Joint Muscle)이 다. 가자미근의 경우 하지의 평균 근 활성도에서는 통계적 으로 유의한 차이가 나타났으며, 사후분석결과 인조잔디가 천연잔디에 비해 더 큰 평균 근 활성도를 보였다. Lee et al. (2013)은 지면 반발계수에 따른 하지의 근 활성도 분 석결과, 지면의 반발계수가 높을수록 하지의 근 활성도가 크게 나타났다고 하였고, 근 활성도가 클수록 상대적으로 큰 부하가 근육에 전달되는 것으로 이는 부상의 위험이 크 다고 하였다(Apell et al., 1992; Newham et al., 1983). 지면의 반발계수를 알아보는 수직 볼 리바운드(vertical ball rebound) 실험에서 인조잔디가 천연잔디에 비해 수 직 볼 리바운드의 높이가 약 2 배 이상 높게 나타났다(Lee et al., 2006). 즉, 인조잔디는 천연잔디보다 반발계수가 높으며, 본 연구에서 인조잔디의 평균 근 활성도가 천연잔 디보다 통계적으로 더 크게 나타난 결과와 일치한다. 이러 한 결과는 인조잔디에서 훈련 시 가자미근의 부상위험이 천연잔디보다 높다고 할 수 있으며, 인조잔디에서 훈련 및 지도 시 주의가 필요하며 부상을 예방하기 위한 가자미근 의 선택적 근력 트레이닝과 함께 충분한 스트레칭과 휴식 이 필요하다고 판단된다.

비복근은 발목의 저측굴곡과 무릎의 굴곡(flexion) 움 직임에서 주동근의 역할을 하는 근육이며, 2 개의 관절을 지나는 두관절 근육(Two Joint Muscle)이다. 내비복근 과 외비복근의 경우 하지의 평균 근 활성도에서는 천연잔 디, 맨땅, 인조잔디 순으로 근 활성도가 더 크게 나타났지 만 통계적으로 유의한 차이는 나타나지 않았다. 이는 실 험을 한 시기로 인해 유의한 차이가 나지 않은 것으로 유 추해 볼 수 있다. 실험의 시기는 2 월로 미끄럼 저항, 견인 력, 반발계수가 1 년 중 가장 작은 차이를 보이는 시기이다 (Park, 2007). 즉, 천연잔디의 생육이 가장 활발한 시기인 여름의 경우 천연잔디와 인조잔디의 근 활성도 차이는 더 많이 나타날 것으로 판단된다. 추후 계절별 그라운드 상태 에 따른 근활성도의 차이를 규명하는 연구가 필요할 것으 
로 제언한다.

단비골근은 1 개의 관절을 지나는 한관절 근육으로 발 목의 저측굴곡과 외번(eversion) 움직임에서 주동근으로 작용하고 발목의 내번(inversion) 움직임에서 길항근으 로 작용한다. 단비골근의 경우 하지의 평균 근 활성도에 서는 통계적으로 유의한 차이가 나타났으며, 사후분석결 과 인조잔디가 천연잔디에 비해 더 크게 나타났다. 본 실 험의 전진 사이드 스텝은 좌측과 우측으로 발이 이동하면 서 앞으로 나가는 동작으로 단비골근은 발목의 외번에 주 동근의 역할과 내번에 길항근의 작용을 동시에 하고 있 다. 이는 Villwock et al. (2009)이 지적한 것처럼, 회전강 성과 회전견인력이 큰 인조잔디가 회전강성과 회전견인 력이 낮은 천연잔디보다 평균 근 활성도가 더 크게 나타 난 것으로 판단된다.

인조잔디가 천연잔디와 맨땅에 비해 하지의 근 활성 도가 크게 나타난 것은 인조잔디에서 훈련 시 하지근육에 부하가 가장 많이 가해진다고 볼 수 있다(Apell et al., 1992; Newham et al., 1983). 근육에 많은 부하가 가해 지면 근 피로를 유발하게 되고(Davis \& Walsh, 2010) 충분한 휴식을 취하지 않았을 경우 근 피로도가 증가한다 (Callahan et al., 2009). 만약 오랜 시간 지속된 훈련 상 황이라면 근 피로가 발생하게 되면서 관절의 움직임과 정 확성이 감소되어 부상의 위험이 높아지게 된다(Chabran et al., 2002). 결과적으로, 인조잔디는 천연잔디에 비해 서 지면의 반발계수가 높기 때문에 하지의 부상 가능성 이 높으며, 운동선수들이나 생활체육 동호인의 경우 장기 간 인조잔디에서 훈련을 할 경우 근 피로를 유발 할 수 있 는 가능성이 천연잔디보다 높기 때문에 충분한 스트레칭 과 휴식을 취해야 하고, 트레이닝을 통해 하지근육의 강화 를 해주는 것이 중요하다고 판단된다. 본 연구는 상대적으 로 적은 인원 (15명)으로 진행된 연구이기 때문에 샘플 사 이즈가 부족하여 연구의 한계를 가진다. 추후 더 많은 샘 플 사이즈를 확보하여 통계적 파워를 향상시키는 후속연 구가 필요할 것으로 제언한다.

\section{결론 및 제언}

본 연구의 목적은 그라운드 형태(천연잔디, 인조잔다, 맨땅)별 하지 근육(전경골근, 가자미근, 내비복근, 외비 복근, 단비골근)의 평균 근 활성도를 비교 분석하는 것으
로서 다음과 같은 결론을 얻었다. 가자미근과 단비골근 의 평균 근 활성도에서 통계적으로 유의하게 나타났으며, 사후분석결과 인조잔디가 천연잔디에 비해 더 크게 나타 났다. 이는 오랜기간 인조잔디에서 장시간 고강도 운동을 하게 되면 천연잔디에 비해 향후 그라운드의 형태에 따른 지면반력과 영상분석을 통해서 부상을 예방하기 위한 심 도 있는 연구가 필요하며, 계절에 따른 그라운드의 잔디길 이와 온도에 따른 차이를 규명하는 연구가 필요할 것으로 제안한다.

\section{참고문헌}

Andersson, H., Ekblom, B., \& Krustrup, P. (2008). Elite football on artificial turf versus natural grass: Movement patterns, technical standards, and player impressions, Journal of Sports Sciences, 26(2), 113-122.

Aoki, H., Kohno, T., Fujiya, H., Kato, H., Yatabe, K., Morikawa, T., \& Seki, J. (2010). Incidence of injury among adolescent soccer players: a comparative study of artificial and natural grass turfs. Clinical Journal of Sport Medicine, 20(1), 1-7.

Apell, H. J., Soares, J. M., \& Duarte, J. A. (1992). Exercise, muscle damage and fatigue. Sports Medicine, 13(2), 108-115.

Callahan, D. M., Foulis, S. A., \& Kent-Braun, J. A. (2009). Agerelated fatigue resistance in the knee extensor muscles is specific to contraction mode. Muscle \& Nerve, 39(5), 692702.

Chabran, E., Maton, B., \& Fourment, A. (2002). Effects of postural muscle fatigue on the relation between segmental posture and movement. Journal of Electromyography and Kinesiology, 12(1), 67-79.

Choi, J. S. (2010). The study about injury of youth soccer players in type of ground. Master's thesis, Gachon University.

Davis, M. P., \& Walsh, D. (2010). Mechanisms of fatigue. The Journal of Supportive Oncology, 8, 164-174.

Dowling, A., Corazza, S., Chaudhari, A., \& Andriacchi, T. (2010). Shoe-surface friction influences movement strategies during a sidestep cutting task: implications for anterior cruciate ligament injury risk. American Journal of Sports Medicine, $38(3), 478-485$.

Dragoo, J., \& Braun, H. (2010). The effect of playing surface on injury rate: A review of the current literature. Sports Medicine, 30(11), 981-990. 
Ekstrand, J., Hägglund, M., \& Fuller, C. (2011). Comparison of injuries sustained on artificial turf and grass by male and female elite football players. Scandinavian Journal of Medicine and Science in Sports, 21(6), 824-832.

Ford, K., Manson, N., Evans, B., Myer, G., Gwin, R., Heigh Jr., R., \& Hewett, T. (2006). Comparison if in-shoe foot loading patterns on natural grass and synthetic turf. Journal of Science and Medicine in Sport, 9(6), 433-440.

Fuller, C., Dick, R., Corlette, J., \& Schmalz, R. (2007). Comparison of the incidence, nature and cause of injuries sustained on grass and new generation artificial turf by male and female football players. Part 1: match injuries. Journal of Sports Medicine, 41(Suppl 1), i20-i26.

Fuller, C., Dick, R., Corlette, J., \& Schmalz, R. (2007). Comparison of the incidence, nature and cause of injuries sustained on grass and new generation artificial turf by male and female football players. Part 2: training injuries. Journal of Sports Medicine, 41(Suppl 1), i27-i32.

Fuller, C., Clarke, L., \& Molloy, M. (2010). Risk of injury associated with rugby union played on artificial turf. Journal of Sports Sciences, 28(5), 563-570.

Hermens, H. J., Freriks, B., Merletti, R., Hagg, G., Stegeman, D. F., Blok, J., Rau, G., \& Dissel-horst-Klug, C. (1999). SENIAM 8: European recommendations for surface elecoromyography, Roessingh Research and Development, ISBN 90-75452-15-2.

Jang, S. W., Lee, K. K., Lee, D. T. et al. (2011). Pattern analysis of the patterns of sliding and tackle between artificial turf and natural grass ground. The Official Journal of the Korean Association of Certified Exercise Professionals, 13(1), 33-41.

Jin, Y. W., Park, J. Y., \& Shin, S. H. (2006). Biomechanical research of natural turf soccer shoes and artificial turf soccer shoes. Korean Journal of Sports Biomechanics, 127-135.

Kang, K. W. (2008). Understanding of characteristic and function of artificial turf in soccer field. Sports Science, 105, 76-83.

Kim, T. W., Kong, S. J., Kil, S. K. et al. (2013). Electromyographic analysis theory and application. Hanmi book.

Korea Sports Safety Foundation (2016). 2015 report of sports safety accident, 1-506.

Lee, J, P., Park, H, C., \& Kim, D, H., (2006). Comparison of play ability of soccer fields with natural turfgrass, artificial furf and bare ground. Weed \& Turfgrass Science, 20(2), 203-211.

Lee, J. S., Kim, C. G., \& Yoon, S. J. (2013). The effects of different surface coefficient of restitution and drop height on vertical ground reaction force, joint angular velocity, moment and muscle activity during drop landing. The Official Journal of the Korean Association of Certified Exercise Professionals, 15(2), 93-104.

Ma, S. R., \& An, S. J. (2012). Effect of high-heel shoes on muscle activity of the lower limbs. PNF and Movement, 10(1), 35-41.

McNitt, A., Landschoot, P., \& Waddington, D. (2004). Effects of turfgrass, cutting height and soil conditions on traction. ISHS Acta Horticulture 661: International Conference on Turfgrass Management and Science for Fields, 39-48.

Newham, D. J., McPhail, G., Mills, K. R., Edwards, R. H. T. (1983). Ultrastructural changes after concentric and eccentric contractions of human muscle. Journal of Neurological Sciences, 61(1), 109-122.

Park, H. C. (2007). The comparison of playing quality of turf grasses in soccer field. Master's thesis, Konkuk University.

Park, K. M., Hong, K, Y., Hur, S., \& Jang, J. H. (2011). Comparison of muscle damage indices and fatigue substances as playing the soccer game between artificial turf and natural grass field. Journal of Sport and Leisure Studies, 46(2), 1055-1063.

Park, S. K., Lee, J. S., Park, S. B., \& Darren, S. (2009). Changes in knee joint loading on infilled turf with different soccer cleat designs. Korean Journal of Sports Biomechanics, 19(2), 369-377.

Reyneri, A., \& Bruno, G. (2004). Effects of wear and turf properties on playing quality for soccer. ISHS Acta Horticulture 661: International Conference on Turfgrass Management and Science for Fields, 295-300.

Seon, M. J. (2018). The effect of the stud types of soccer shoes on the muscle activity of the lower limbs. Unpulbished master's thesis. Chungang University.

Soligard, T., Bahr, R., \& Andersen, T. (2012). Injury risk on artificial turf and grass in youth tournament football. Scandinavian Journal of Medicine and Science in Sports, 22(3), 356-361.

Steffen, K., Andersern, T., \& Bahr, R. (2007). Risk of injury on artificial turf and natural grass in young female football players. Journal of Sports Medicine, 41(Suppl 1), i33-i37.

Villwock, M., Meyer, E., Powell, J., Fouty, A., \& Haut, R. (2009). Football playing surface and shoe design affect rotational traction. American Journal of Sports Medicine, 37(3), 518-525. 


\section{축구장 그라운드 형태가 전진 사이드 스텝 시 하지의 근활성도에 미치는 영향}

이현빈 · 임비오(중앙대학교)

〔목적〕 본 연구는 고등학교 남자 축구선수 15 명을 대상으로 축구장 그라운드의 형태(천연잔디, 인조잔디, 맨땅)에 따른 전진 사이드 스텝 시 하지 근육(전경골근, 가자미근, 내비복근, 외비복근, 비골근)의 평균 근활 성도의 차이를 규명하는 것이다. 〔방법) 본 연구의 목적을 달성하기 위해서 하지의 5 가지 근육(전경골근, 가 자미근, 내비복근, 외비복근, 단비골근)에 전극을 부착하고, 최대수의적수축(\%MVIC)를 3 회 반복 측정 하였 으며, 본 실험에서는 전진 사이드 스텝 시 축구장 그라운드의 형태에 따른 하지 근육의 평균 근활성도의 통계 적 차이를 알아보기 위해서 반복이 있는 일원변량분석을 실시하였으며, 사후검증은 Scheffe 방식을 활용하였 다. 〔결과〕 가자미근과 단비골근의 평균 근 활성도에서 인조잔디는 천연잔디에 비해 유의미하게 더 높게 나타 났다. (결론) 가자미근과 단비골근의 평균 근 활성도에서 인조잔디가 천연잔디에 비해 더 크게 나타났다. 이는 인조잔디가 천연잔디에 비해 하지 근육에 더 많은 부하가 전달된 것을 의미하며, 부상의 위험이 더 크다. 또한 동일한 동작을 반복했을 때 인조잔디가 천연잔디에 비해 더 많은 피로도를 유발할 수 있으며, 충분한 휴식과 스트레칭을 하지 않는다면 부상 가능성이 더 높아질 수 있어 필드에서 지도 시 주의가 요구된다.

주요어: 축구, 운동장형태, 하지, 근활성도 